\title{
6 Abrasive Wear between Rough Surfaces in Deep Drawing
}

\author{
M.A. Masen \& M.B. de Rooij \\ University of Twente, Twente Institute of Mechanics \\ Surface Technology and Tribology Group \\ P.O.Box 217, 7500 AE Enschede, The Netherlands \\ Phone: +31 53489 4390, e-mail: m.a.masen@ctw.utwente.nl
}

\begin{abstract}
A recent development in sheet metal forming industry is the application of tailored blanks: blanks prepared from separate pieces of sheet material, welded together prior to the forming process. The pieces of sheet material can have different properties, enabling weight reduction of components, corrosion resistance using cathodic protection or the possibility to create local weak spots, resulting in well defined deformation zones in the event of an accident (e.g. crash zones in automotive applications). However, a major draw back in the utilisation of these pre-welded or tailored blanks is that the weld between the pieces of sheet exhibits increased hardness and roughness, leading to possible abrasive wear of the sheet metal forming tool [1]. In this work a model is developed describing the abrasive wear of deep drawing dies caused by the application of tailored blanks.
\end{abstract}

Many surface contact models are based on the assumption that surfaces are composed of a collection of small asperities of which the tips are equally sized and spherically shaped and have some kind of statistical height distribution. This approach w as used in 1966 by Greenwood and Williamson [2] and was successfully followed by many researchers during the following decades. The statistical representation of surface topography enables calculation of contact forces and asperity deformations with reasonable accuracy using well-established equations. Although this approach has proven to be suitable for static contact situations, alternative representations of the surface topography are required $w$ hen modelling abrasive wear. In the current work an elastoplastic contact model is developed in which a representation of the surface topography is obtained by best-fit approximations of the microcontacts, obtained from real, measured surface height data. In this deterministic surface representation the tips of the contacting asperities are assumed to have an ellipsoidal shape. Given the material parameters and contact conditions, the load and deformation of a single asperity can be computed. Subsequently, the wear induced by each individual asperity is obtained by inserting its size and shape and the conditions into a "single asperity micro-abrasion model". By summing the contributions of all individual asperities, the total abrasive w ear volume is obtained. The results of the developed abrasive wear model are compared with results obtained using a statistical approach.

\section{References:}

[1] Vermeulen, M., (1997), Effect of Pre-Welded Blanks on the W ear of Deep Drawing Tools, Abstracts of papers, 1st World Tribology Congress, London, pp. 333, ISBN 1860581099.

[2] Greenwood, J.A., and Williamson, J.B.P., (1966), Contact of nominally flat surfaces, Proc. R. Soc. Lond. A, Vol. 295, pp. $300-319$. 